\title{
Thermochemical energy storage - from fundamental research to TRL IV
}

\author{
Piotr Babiński ${ }^{1}$, Michalina Kotyczka - Morańska ${ }^{1}$, and Jarosław Zuwała ${ }^{1, *}$ \\ ${ }^{1}$ Institute for Chemical Processing of Coal, Zamkowa 1 St., 41-803 Zabrze, Poland
}

\begin{abstract}
The paper presents the results of the fundamental research devoted to the application of $\mathrm{MgSO}_{4}$ as a heat carrier for thermochemical seasonal storage system devoted for household application followed by the results of $35 \mathrm{kWh}$ storage tank (TRL IV) charging and discharging tests. Seasonal thermochemical heat storage, based on the reversible reactions of hydratation and dehydratation of a solid medium gives an opportunity to accumulate the energy with a storage capacity exceeding $300-400 \mathrm{kWh} / \mathrm{m}^{3}$.
\end{abstract}

\section{Introduction}

Households and tertiary buildings are responsible for the consumption of approximately $46 \%$ of all energies and at the same time cause around $19 \%$ of the total $\mathrm{CO}_{2}$ emissions. In Poland, fossil fuels combustion (coal, natural gas) in individual (residential) and centralized (district) heating covering heating and hot tap water demands are responsible for $56 \%$ and $41 \%$ of energy supplies respectively. In this context, achieving $\mathrm{CO}_{2}$ reduction goals in the housing \& tertiary buildings sector via improving the energy performance of the buildings is a key issue. Thermal energy storage systems applied in the housing sector could make an important contribution to the reduction of fossil fuel consumption especially when applied in low-energy and zero-emission buildings. Designing and implementation of energy an cost effective energy storage devices would enhance the use of renewable energy sources. Summer solar energy radiation on the low-energy buildings roofs is much greater comparing to the needs for annual space heating and hot tap water. Thus, it would be reasonable to apply long term storage in household heating systems. Such storage could be accomplished by the use of sensible heat storage, latent heat storage, physical sorption and chemical heat storage, offering the highest potential for seasonal storage: highest energy density and lowest heat losses.

The desire to reduce $\mathrm{CO}_{2}$ emissions prompts us to look for new solutions for the supply and storage of thermal energy for residential, office buildings or production halls. Because of the climate in Poland, heat consumption occurs mainly in the winter season, where the possibility of obtaining renewable energy, particularly solar energy is very low. Article presents the possibility of thermochemical heat storage from various low-temperature sources. Storing of thermal energy in summer and using it during winter time will allow covering the residential heating demands.

\footnotetext{
*Corresponding author: jzuwala@ichpw.pl
} 
On the basis of literature research [1-5], the authors proposed the development of seasonal technology for accumulation of thermal energy (solar) obtained by means of solar collectors. Heat accumulation is carried out during the summer season when it is possible to collect it. On the other hand, heat recovery occurs in the winter season for the heating of buildings. The first one is shown in Figure 1 (heat accumulation) and Figure 2 (energy recovery).

(a)
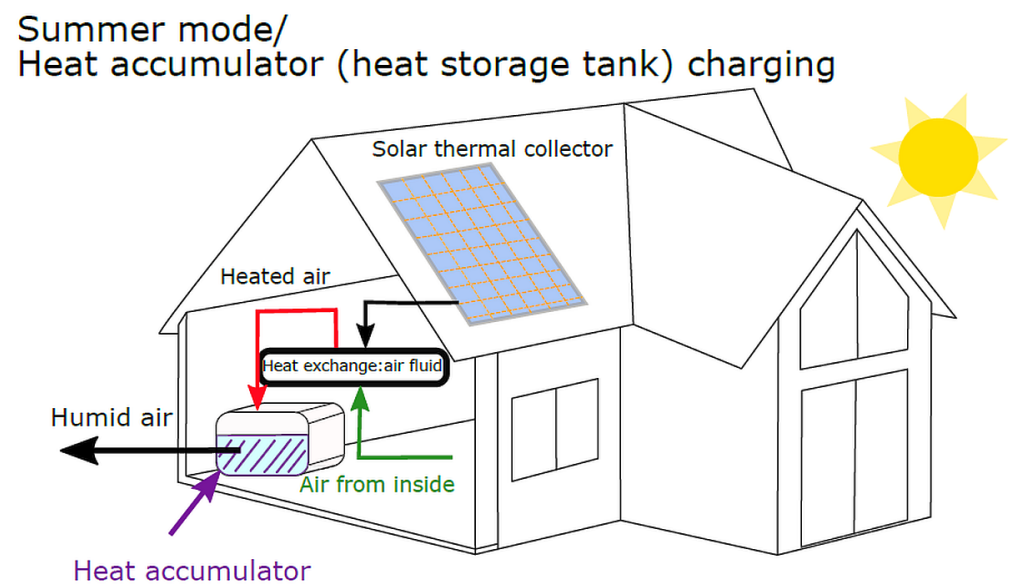

(b)

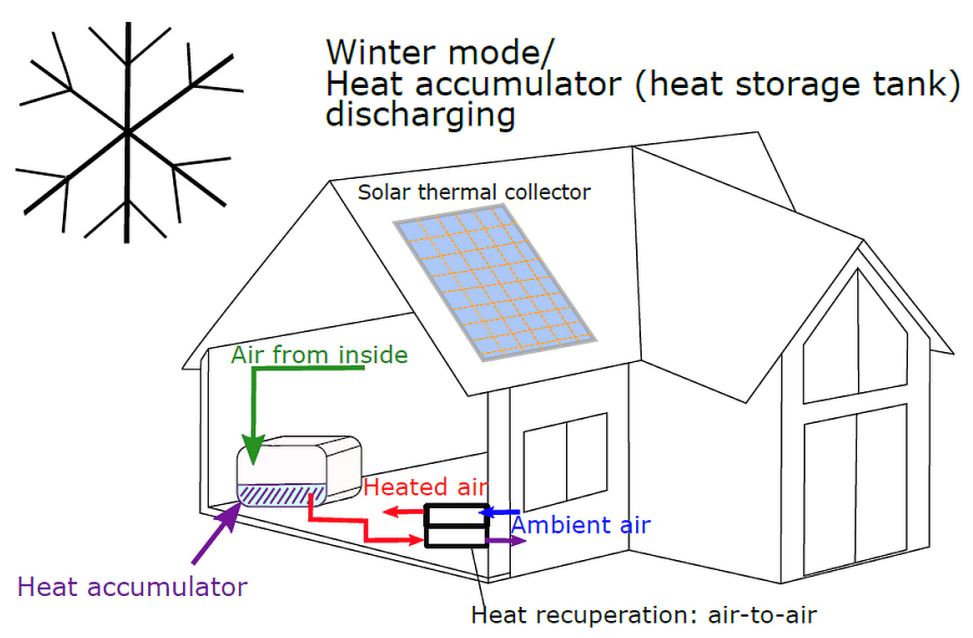

Fig.1 Idea of seasonal heat storage - (a) summer mode - heat accumulator charging, (b) - winter mode - heat accumulator discharging

In solar collectors the circulating glycol is heated to about $110-120^{\circ} \mathrm{C}$. Glycol is directed to the heat exchanger where the air is heated to $60-90^{\circ} \mathrm{C}$. The air pumped by an air blower and directed to the heat storage has a low relative humidity, thanks to which the dehydration process of $\mathrm{MgSO}_{4} \cdot 7 \mathrm{H}_{2} \mathrm{O}$ to $\mathrm{MgSO}_{4} \cdot \mathrm{H}_{2} \mathrm{O}$ is possible. Exhaust air is used for preheating the inlet air in the recuperator. Ambient air is introduced into the building via a blower. In the recuperator, the air is heated up by means of warm air leaving the energy storage unit. Indoor ventilation air is used to purge magnesium sulphate. Magnesium 
sulphate $\mathrm{MgSO}_{4} \cdot \mathrm{H}_{2} \mathrm{O}$ absorbs moisture and it's an exothermic process. Thanks to this, the flowing air is heated, and then used in the recuperator to heat up the ventilation (inlet) air.

\section{Magnesium sulphate fixed bed energy storage concept}

The idea of the thermochemical energy storage is based on the reversible chemical reactions where the creation of reaction products is exothermic part of the reversible reaction and the creation of the reactants is the endothermic part.

The key stage of the research was to find a new compound (type) of energy carrier, that will be based on cheap and available chemical agents. Numerous reversible reactions and materials can be considered for the heat storage. First, the material reaction temperature must result from the available heat sources potential whereas the material itself must be safe for humans' health. Amongst few candidates, $\mathrm{MgSO}_{4} \cdot 7 \mathrm{H}_{2} \mathrm{O}$ (magnesium salt) seems to be very promising material for chemical energy storage, offering high energy density. It accumulates heat in the phase change reaction described by the following equation:

$$
\mathrm{MgSO}_{4}(\mathrm{~s})+7 \mathrm{H}_{2} \mathrm{O}(\mathrm{g})<=\mathrm{MgSO}_{4} \cdot 7 \mathrm{H}_{2} \mathrm{O}(\mathrm{s}) \quad+411 \mathrm{~kJ} / \mathrm{mol} \mathrm{MgSO}_{4} \text {. }
$$

Proposed material of heat carrier was pelletised and applied in the in-house made fixed bed heat storage tank (chemical reactor). For the right operation of the reactor, the material of the proper particle size should be used to keep low pressure drop while air flow through the bed. In the regarded household application, first the dehydration of $\mathrm{MgSO}_{4} \cdot 7 \mathrm{H}_{2} \mathrm{O}$ with a dry air flow at a temperature of approx. $80^{\circ} \mathrm{C}$ takes place, which is presented in Figure 2. While charging the accumulator takes place, subsequent layers of the salt are dehydrated, causing the "forehead" of the reaction to move upward. In the layer where the dehydration occurs, the temperature decreases because the enthalpy of the air flow is used for this reaction.

(a)

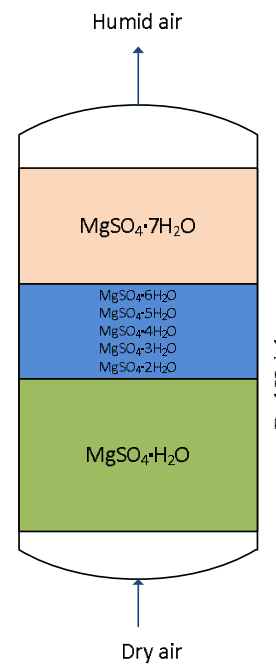

(b)

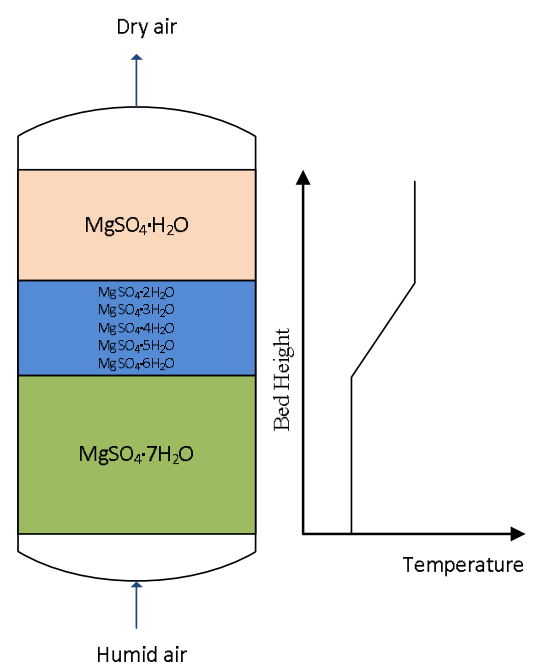

Fig. 2 The idea of heat accumulation (a) and heat recovery (b) in a heat accumulator with magnesium sulphate. 
Discharging the heat storage tank is based on the reverse process with the humid air (with increased level of moisture comparing to the "dry air") being added to the accumulator. This results in the hydration of magnesium sulphate, which is an exothermic reaction and the stream of flowing air is heated up. As in the case of recharging, also in this case the "front of reaction" layer moves through the accumulator.

\section{Analysis of technological variants covering the demand for heat in an exemplary single-family building}

Preliminary comparison of the volume of heat storage $66 \mathrm{kWh} /$ day $\left(120 \mathrm{~m}^{2}\right.$ house with the annual demand of $100 \mathrm{kWh} / \mathrm{m}^{2}$ ) in relation to the other storage media or potential energy carriers (fuels) is presented in Table 1.

Table 1 Comparison of different storage media and fuels

\begin{tabular}{|l|r|r|r|r|l|}
\hline & \multicolumn{1}{|c|}{ MgSO $_{4}$} & Natural gas & Paraffin & $\begin{array}{l}\text { Hot water } \\
\left(\mathbf{3 0 - 8 0}^{\circ} \mathbf{C}\right)\end{array}$ & \multicolumn{1}{l|}{ Coal } \\
\hline $\begin{array}{l}\text { Calorific value / } \\
\text { storage capacity }\end{array}$ & $1300 \mathrm{MJ} / \mathrm{t}$ & $40 \mathrm{MJ} / \mathrm{m}^{3}$ & $200 \mathrm{MJ} / \mathrm{t}$ & $200 \mathrm{MJ} / \mathrm{t}$ & $20000 \mathrm{MJ} / \mathrm{t}$ \\
\hline $\begin{array}{l}\text { Amount of fuel / } \\
\text { storage }\end{array}$ & $180 \mathrm{~kg}$ & $6,0 \mathrm{~m}^{3}$ & $1180 \mathrm{~kg}$ & $1130 \mathrm{~kg}$ & $12 \mathrm{~kg}$ \\
\hline
\end{tabular}

As it can be seen, the size of the thermochemical heat store in comparison to other heat storage (water and paraffin) is very beneficial (about a 10-fold reduction in the volume of the storage medium).

\section{Thermodynamic analysis of the process}

The thermodynamic analysis of the process was carried out, with the following assumptions:

- the equilibrium composition of $1 \mathrm{kmol}$ of magnesium sulphate was determined, assuming subsequent mole fraction of water vapor corresponding to $100 \%$ of the relative humidity of the air at a temperature of 0 to $100^{\circ} \mathrm{C}$;

- the presence of magnesium sulphate hydrates from 0 to 7 molecules of water.

The analysis was carried out using the software of HSC Chemistry 7.0 from Outotec, and the results of the analysis are presented in the Fig. 3 .

The data from thermodynamic equilibria calculations were collected, converted and presented in the form of mass loss of water as a function of temperature for particular contents of water vapor in the air. Next, points corresponding to the thermodynamic balance of magnesium sulphate for the content of water vapor corresponding to $100 \%$ relative humidity at a given temperature were marked on the graphs. These points form the "operating" line of the heat accumulator (in Fig. 3). Accumulator effective operation is possible in the area between the axis $x, y$, and the operating line. Above this line condensation of water vapour in the air occurs and is highly unfavourable from the point of view of the process, due to the possibility of water condensation and dissolution of magnesium sulphate. The graph in Figure 3 also provides information, that the maximum heat storage capacity can be up to approx. $80 \%$ of the theoretical value. 


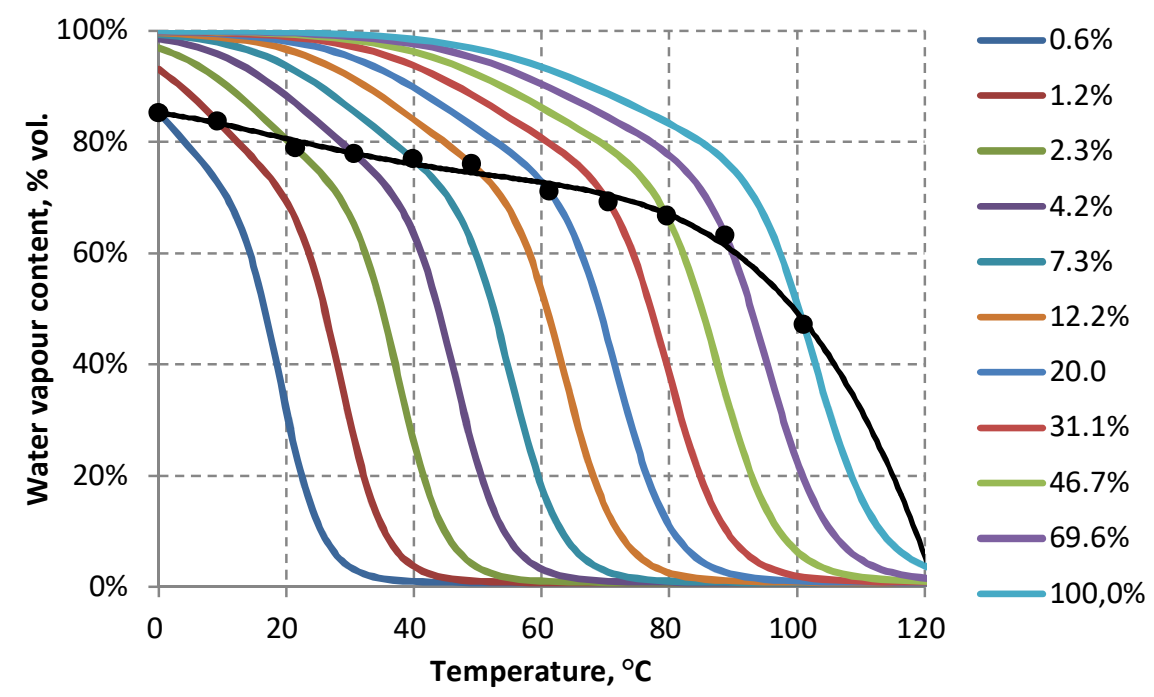

Fig. 3 The operating range of the heat accumulator.

\section{Experimental research}

Thermogravimetric studies were conducted using a TG-HP 150s pressure thermogravimetric analyser from TA Instruments due to the possibility of dispensing moist air in this apparatus (Fig.4). The humid air was obtained by dispensing air from the bottle through a water scrubber.

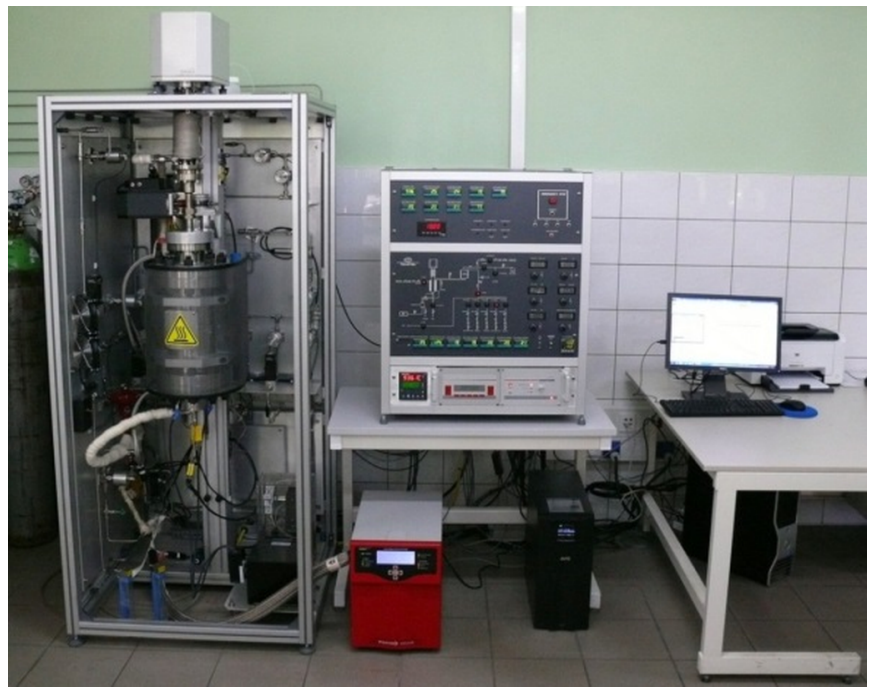

Fig. 4 View of the thermogravimetric pressure thermogravimetric analyser.

In the pressure thermogravimetric analyser three successive cycles of heat carrier $\mathrm{MgSO}_{4}$ testing were carried out, with dehydration being carried out at a temperature of about $100^{\circ} \mathrm{C}$, and hydration at a temperature of about $23^{\circ} \mathrm{C}$. Dehydration was carried out for about 22 hours and hydration for about 28 hours. The dehydration and hydration experiments were carried out to obtain a relatively constant mass of the heat carrier. The 
hydration was carried out with a steady vapor content of $2.3 \%$ by volume (equilibrium at $20^{\circ} \mathrm{C}$ - water temperature in the scrubber)). The graphs presented below (Fig. 5) present three full cycles of magnesium sulphate performed in a pressure thermogravimetric analyser.

(a)

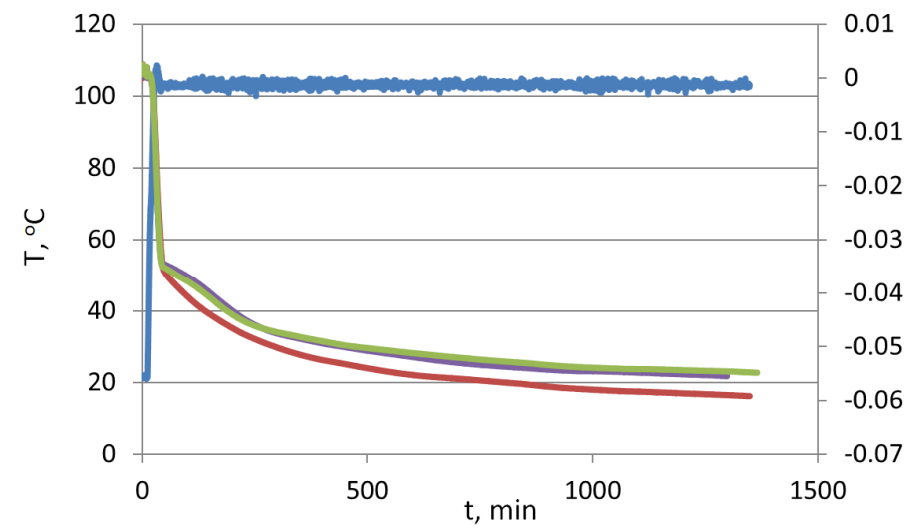

(b)

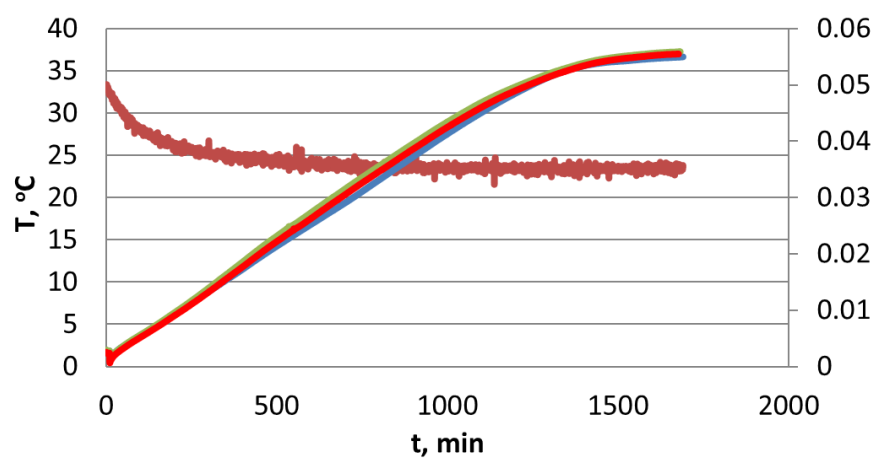

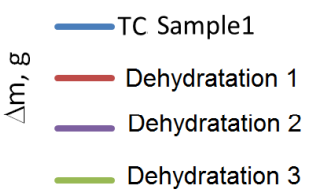

a $\longrightarrow$ TC Sample

छे Hydratation 1

Hydratation 2

Hydratation 3

Fig. 5 Comparison of hydration and dehydration of carrier during subsequent cycles

As can be seen, the carrier exhibits stability in three cycles of hydration and dehydration and it is still active in the process. The next level of research was conducted on a largescale scale, using $150 \mathrm{~kg}$ of carrier, which formed into pellets The aim of this research was to test the possibilities of air heating with the use of a batch of ca. $150 \mathrm{~kg} \mathrm{MgSO} \cdot 7 \mathrm{H}_{2} \mathrm{O}$. The test stand for testing the thermal energy storage capacity was constructed in IChPW, and the scheme of the bench scale reactor is presented in Figure 6. 
(a)

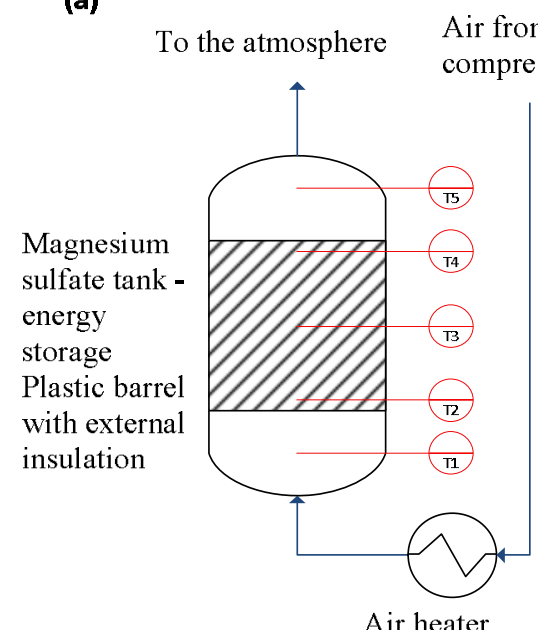

(b)

To the atmosphere

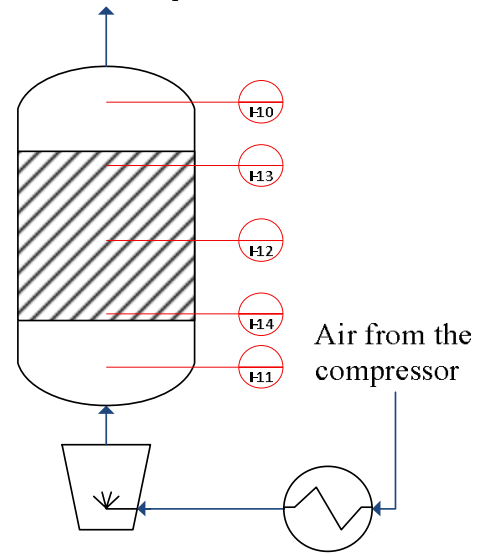

A scrubber with water for air humidification
Air heater

Fig. 6 Scheme of the test bench for thermal energy storage by the carrier $\left(\mathrm{MgSO}_{4}\right)$.

The test bench reactor was equipped with a plastic tank (barrel), with a capacity of 0.18 $\mathrm{m} 3$, in which $150 \mathrm{~kg}$ of magnesium sulphate was placed. The process air was supplied with a plastic nozzle from the bottom, and the air flow direction was vertical upwards. From above, the tank was closed with a plastic cover in which an air outlet was drilled, through which thermocouples and Pt-100 sensors were also introduced into the tank. The heat accumulation was based on the dehydration of the hydrated salt of $\mathrm{MgSO}_{4} \cdot 7 \mathrm{H}_{2} \mathrm{O}$ to the monohydrate form by an air stream at a temperature of about $80^{\circ} \mathrm{C}$. The accumulator charging process was run average for 8 hours per day, thus reflecting the real conditions when it is possible to use solar energy from solar collectors. The process of heat accumulation began on August 22 $2^{\text {nd }}$ and lasted until October $17^{\text {th }}$ 2017. At that time, the $\mathrm{MgSO}_{4}$ tank was weighed weekly and the weight loss was controlled. The air flow was set at $10 \mathrm{Nm}^{3} / \mathrm{h}$.

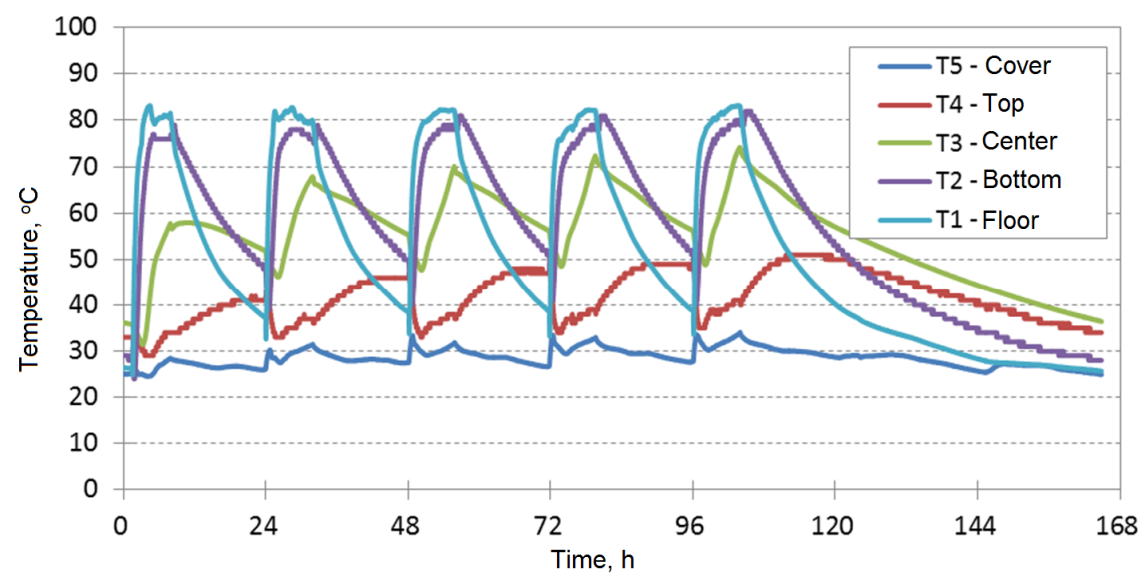

Fig. 7 Heat accumulation - 5 working days 
The following figure (Fig. 7) shows the temperature in the tank during heat accumulation. The graph shows the entire week of heat accumulation (5 working days).

As can be seen, feeding dry air flow to the tank caused the removal of water of hydration and storage of thermal energy. The above graphs show how heat is accumulated. The inlet air temperature is around $80^{\circ} \mathrm{C}$, the temperature in the tank only slightly increases. The subsequent $\mathrm{MgSO}_{4}$ layers are dehydrated, taking most of the heat from the air stream. In the presented graph from the 5th week, the lowest $\mathrm{MgSO}_{4}$ layer is dehydrated and it is rapidly heated to over $70^{\circ} \mathrm{C}$. at the same time, an increase in temperature in the central part of the bed is visible, suggesting that the "head of reaction" is shifting through the central part of the bed. The layers of the bed after heat accumulation (a bed of dehydrated salt) are relatively quickly heated, unlike the hydrated salt, because the temperature increase is utilized for the dehydration reaction.

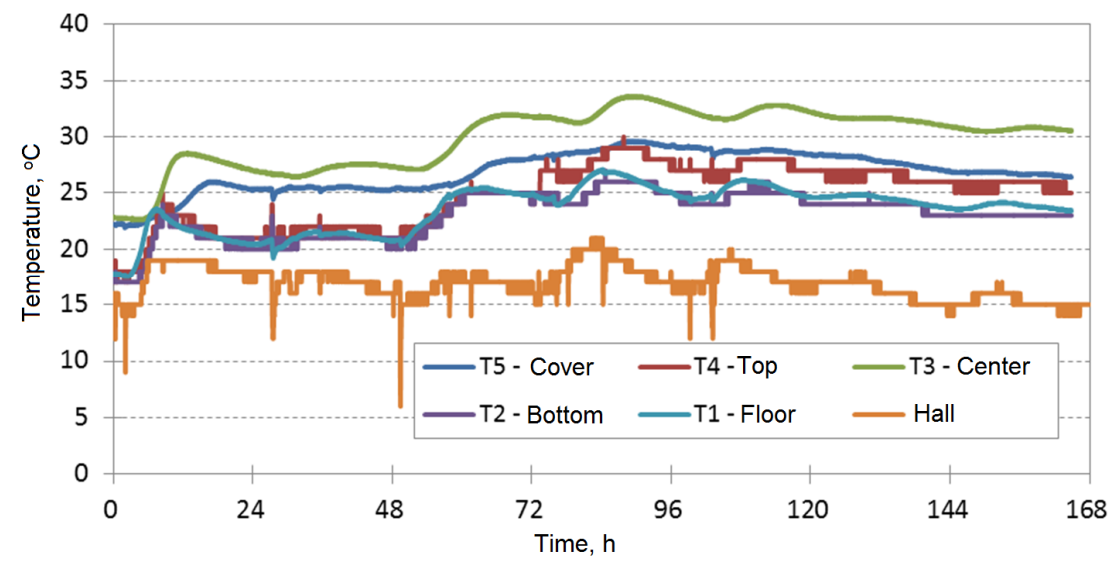

Fig. 8 Heat recovery - week 7

Figure 9 shows a graph of the change in the mass of the magnesium sulphate tank as a function of time during accumulator charging and during its discharge.

(a)

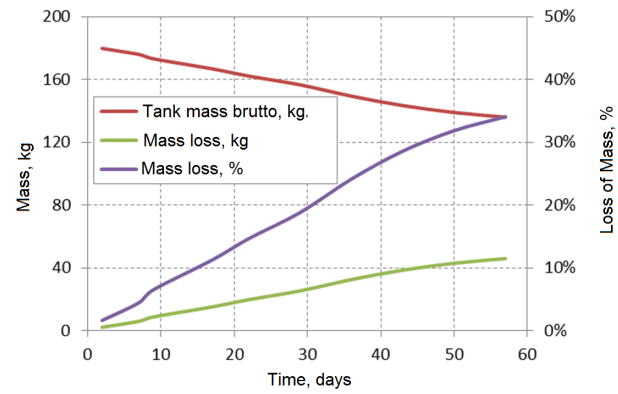

(b)

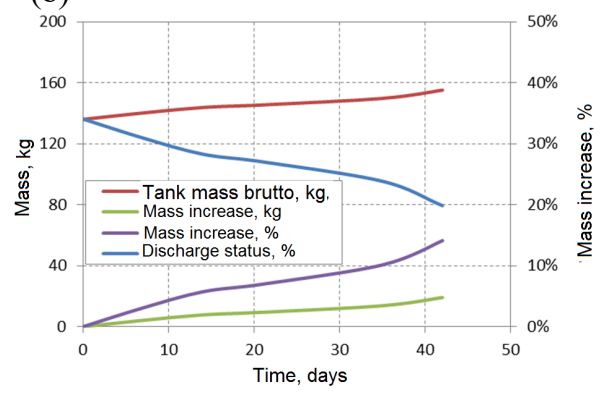

Fig. 9 Change in the mass of the magnesium sulphate tank as a function of time during accumulator charging (a) and during its discharge (b)

On October $17^{\text {th }}$, the heat recovery process began (Fig.8). The air from the compressor with known flow was directed to a water scrubber, which was supposed to saturate the air with water vapor and then regulate the inlet temperature of the air. First, the inlet temperature was about $20^{\circ} \mathrm{C}$, then about $25^{\circ} \mathrm{C}$ and it was directed to a tank with magnesium sulfate. Initially, a flow rate of $15 \mathrm{Nm}^{3} / \mathrm{h}, 10 \mathrm{Nm}^{3} / \mathrm{h}$ was used to finally stay at the flow of $5 \mathrm{Nm}^{3} / \mathrm{h}$. 
It turned out that the increase of the inlet temperature and the parallel content of water vapor in the air caused an increase in the thermal effect. When the inlet temperature was $20^{\circ} \mathrm{C}$, a temperature of about $26^{\circ} \mathrm{C}$ was obtained in the central part of the bed, and when the inlet temperature was $25^{\circ} \mathrm{C}$, the temperature in the middle part was about $33^{\circ} \mathrm{C}$. It goes without saying that in the case of heat recovery, reaction kinetics plays a key role.

As can be seen, some of the accumulated heat has been recovered at the moment. The weight gain is currently around $20 \mathrm{~kg}$, while the weight loss during loading was over $40 \mathrm{~kg}$. There are visible changes in the mass growth rate which resulted from the change of air flow directed to accumulation (in the first two weeks the air flow was 15 and then 10 $\mathrm{Nm}^{3} / \mathrm{h}$. For this reason, the weight gain is slightly larger than in the subsequent period. (after 30 days of operation) the air inlet temperature was increased, which also accelerated the speed of discharging the accumulator.

\section{Conclusions}

The main conclusions of the research carried out were as follows::

- it is possible to accumulate heat using the thermochemical reactions and applying dehydrated magnesium salt- $\mathrm{MgSO}_{4}$ as a heat carrier

- as a heat source of the dehydration process it is possible to use solar heat and the recovered heat can be used for residential heating needs in the low-energy or passive buildings

- effective thermal energy recovery must take be carried out with the use of humid air

- along with the increase of the regeneration air temperature, the water vapor content increases, which results in acceleration of salt hydration and increase of the thermal effect of the process.35kWh storage tank (TRL IV) charging and discharging have been successfully carried out.

- important conclusions can be drawn on the scale-up strategy and further optimizations in the field of the heat carrier itself (more stable pellets) and the storage tank (thermochemical reactor) inner design.

Acknowledgement: Results presented in this paper were obtained during the research works financed by Ministry and Higher Education within the projects „Energy storage identification of the perspective research fields" (No 11.16.014/2016) and "Seasonal thermochemical renewable energy storage" (No. 11.17.014/2017). The authors gratefully acknowledge financial support.

\section{References}

[1] P.A.J. Donkers, S. Beckert, L. Pel, F. Stallmach, M. Steiger, O.C.G. Adanz, J. Phys. Chem. C, 119 (2015)

[2] M. van Essen V., H. A. Zondag, Gores J. Cot, L. P. J. Bleijendaal, M. Bakker, R. Schuitema, W. G. J. van Helden, Z. He, C. C. M. Rindt, J. Sol. Energy Eng 131 (2009)

[3] S. Hongois, F. Kuznik, Ph. Stevens, J.-J. Roux, Sol Energy Mater Sol Cells, 95 (2011)

[4] B. Michel, N. Mazet, S. Mauran, D. Stitou, J. Xu, Energy 47 (2012)

[5] H. Soegijono, B. Soegijono, Res. J. Material Sci., 2 (2014) 